BULLETIN Bulletin hispanique

HISPANIQUE Université Michel de Montaigne Bordeaux

117-1 | 2015

Les poètes des rhéteurs

\title{
Literatura a latere del Setecientos ecuatoriano
}

los fragmentos ibarreños

\section{Patrizia Di Patre}

\section{(2) OpenEdition}

Journals

Edición electrónica

URL: https://journals.openedition.org/bulletinhispanique/3950

DOI: 10.4000/bulletinhispanique.3950

ISSN: $1775-3821$

Editor

Presses universitaires de Bordeaux

Edición impresa

Fecha de publicación: 1 junio 2015

Paginación: 395-404

ISBN: 979-10-300-0174-7

ISSN: 0007-4640

Referencia electrónica

Patrizia Di Patre, «Literatura a latere del Setecientos ecuatoriano», Bulletin hispanique [En línea], 117-1 | 2015, Publicado el 01 septiembre 2015, consultado el 12 febrero 2022. URL: http://

journals.openedition.org/bulletinhispanique/3950 ; DOI: https://doi.org/10.4000/bulletinhispanique. 3950

Este documento fue generado automáticamente el 12 febrero 2022.

Tous droits réservés 


\section{Literatura a latere del Setecientos ecuatoriano}

los fragmentos ibarreños ${ }^{1}$

Patrizia Di Patre

\section{Un recorrido emblemático}

1 El núcleo poético que nos aprestamos a considerar tiene una consistencia exigua, y su carácter fragmentario parece implicar inevitables carencias receptivas. Un detenido análisis revelará por el contrario directrices de alta representatividad, hasta el extremo de la identificación modélica. Los poemas hallados por el doctor José Alejandro López a finales del siglo $\mathrm{XIX}^{2}$ nos remiten a un setecientos complejo, rico en motivos culminantes y, sobre todo, dotado de interna y legible consecuencialidad. A partir de Evia y llegando al prerromanticismo de Aguirre la parábola entera de la poética ecuatoriana halla un fiel reflejo en esta colección de ensayos monacales, con carácter de hábitat autónomo ${ }^{3}$. Nos proponemos dividirlos según las tendencias encontradas (cuando no verdaderas «manos»), en una curvatura ideal de la cronología asumida.

\section{Alfa: sor Antonia o la brusquedad rítmica de Evia}

Invitamos a considerar el siguiente trozo de romance:

Por Antonia soy indigna,

mas por Asunción bien puedo

en vuestra piedad fiada,

ascender a vuestro cielo;

si me culpáis de atrevida

tenéis razón, ya lo veo,

pero, como soy novicia,

no os admirarán mis yerros.

Negué a mis padres y deudos

y el siglo negué por Vos, 
y a todo cerráis los ojos,

¡ay qué terrible dolor!

Lo precioso de la sangre

con la virtud se acompaña;

pues padres y deudos deja

por buscar glorias del alma ${ }^{4}$.

3 He aquí una "arietta» atípica, con un sello extraindividual pero circunscrito. Tenemos por un lado el sentimiento teresiano de un intimismo formal, por el otro ecos apenas audibles de avanzadillas cuasi gongorinas («Lo precioso de la sangre / con la virtud se acompaña»), puras muestras aisladas de un razonamiento que no apunta al triunfo. El rechazo explosivo se debe a una clausura más sosegada que terminante, con valor de cierre impuesto por la aceptabilidad de la hipótesis. Esto concluye sin rematar; explica lo suficiente para no buscar más, sirve de brochazo lógico a las dilataciones barrocas. Si queremos ver otro ejemplo del género, bastará recurrir a las expansiones contenidas de Evia :

Por Sebastiana me anuncia, seré blanco de sus tiros;

dichoso sea mi pecho

si me flecha tal Cupido.

Con velo cubre mis ojos,

sospechas habrá tenido;

pero no, que darles velo

es tratarlos por divinos.

$Y$ pues es tal mi ventura

con un esposo tan rico,

de Buenaventura el nombre

ajustado me ha venido ${ }^{5}$.

El final de ambas piezas es evidentemente «infeliz» ${ }^{6}$, ya lo llamemos falsamente provisional o sin derecho a calificaciones crocianas. Otro rasgo en común proporciona la afluencia maciza de fórmulas razonadas y explicaciones causales (pues, que), anunciadoras del lenguaje científico, y ciertamente ajenas a una poética manierista ${ }^{7}$.

Pero es en la brusquedad rítmica donde más se aprecia la distancia de las formas tradicionales. Los villancicos que siguen poseen un esquema peculiar (hasta podríamos hablar de invención extemporánea). Con apenas un atisbo de rima asonantada, y una irregularidad que apunta a la anarquía (salvo la medida fija), los versos pueden ya considerarse sueltos.

Veamos su esqueleto rítmico a partir de la imagen real:

[A] Dejad ya, pastores, el humilde aprisco, pues os llama el cielo a empleos divinos; llegad a Belén donde en solo un niño veréis cuanto encierra todo el cielo empíreo; al león veréis hecho un corderillo, que amor le dispone tierno sacrificio ${ }^{8}$.

[B] Niño de mis ojos, descansad un rato, 


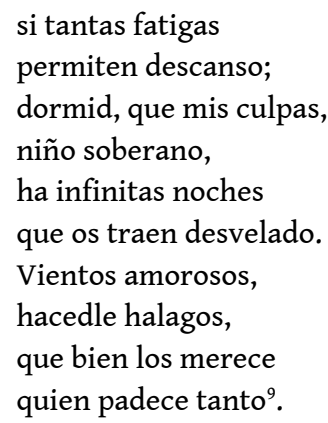

7 Aquí todo es misterio. Comenzando por la laguna relativa al estribillo, a lo mejor debida a causas accidentales, pero a buen seguro intrigante. No se entiende además si los dos fragmentos pertenecen a la misma mano (lo que sugiere la concurrencia en un esquema atípico aunque bien definido), o participan de una obra colectiva. Puede que se tratara de algún certamen interno, o también un divertissement ocioso, al estilo conventual renacentista. En este caso deberíamos concluir que la cuarteta inicial introduce el tema bajo la forma de redondilla modificada («Niño de mis ojos / descansad un rato», etc.), y que su elección se confiaría a un examen posterior. Lo cierto es que el sistema de asonancias escogido, con un régimen interno perfectamente declarado, emparienta a los dos textos por su misma excentricidad: los versos 1 y 3 construyen una extraña sonoridad sobre vocales diferentes (es/os en el primer caso; os /as en el segundo) y la constancia de una «o» siempre alterna. Las monjitas de Ibarra elaboran en definitiva una forma métrica, totalmente revolucionaria y coherente. ¿Impericia técnica o ya desprecio de las reglas?

8 Hay que fijarse también en la ausencia completa de sinuosidades íntimas. No hay un recorrido tortuoso desde el punto de vista psicológico, sino más bien conceptos tradicionales, dogmáticos o tomados de la Escritura. Estas características son propias también de un fragmento alejado ${ }^{10}$, cuyos componentes métricos se han librado definitivamente de las ataduras tradicionales. Se trata de la misma tendencia al verso suelto que releva José López y cita Alejandro Carrión ${ }^{11}$ como ejemplar.

9 También este fragmento puede considerarse emblemático, con una expansión extramelódica muy característica ${ }^{12}$ :

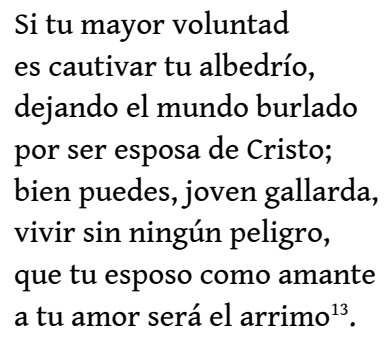

10 Definiciones, como siempre, pseudocientíficas (tal vez derivadas de la prosa mística renacentista), y absoluta claridad conceptual, con una expansión extramelódica de marca americana. Evia se impone todavía.

\section{Adiós, oh dulce María. Tendencia beta}

Lo que tenemos aquí es una melodía declarada, sonoridades plenamente barrocas. Al lado de un recorrido psicológicamente tortuoso y los acentos románticos de Aguirre. Se 
trata de una fase ideal, si no cronológicamente posterior a la precedente ya declarada; se atisba un iluminismo no solo maduro, sino superado.

El primer ejemplo útil podría ofrecerlo un villancico de estricta normatividad, con tipología pertinente:

Tema

Las doce SON DE LA NOCHE, Niño Dios, ¿y no dormís?

Si es amor, ¡ay, Dios, qué dicha!

SI SON CELOS, ¡AY DE MÍ!

Copla

Cuando nacéis, Redentor,

y os ponéis, niño, a llorar,

me pongo a considerar

si es amor;

mas luego pienso, Señor,

mirando vuestros desvelos,

que son celos.

Suspiros doy a los cielos

y digo, viéndoos así:

Si es amor, ¡ay, Dios, qué dicha!

Si son celos, jay de mí! ${ }^{14}$

Comparémoslo con el siguiente, brevísimo fragmento:

Adiós, ¡oh dulce María!,

Adiós, ¡celestial princesa!,

y no olvides a estas hijas

que dejáis de dolor llenas ${ }^{15}$.

¿Cuáles son las peculiaridades de la pieza? Pues un intimismo decididamente contrario al barroco; una armonía cercana a sus manifestaciones clásicas; el ritmo fácil de la plegaria teresiana (diríamos colectiva, si no fuera por la sonora individualidad manifestada).

No sabemos si a la/las representante/s de esta línea se pueda atribuir la lectura positiva de la literatura anterior; lo cierto es que se la ignora (¿desecha?) rotundamente. Esto resaltará mejor en el grupo de las manifestaciones sucesivas, donde la cualidad del himno patriótico se impone sobre cualquier otra connotación. Las sinuosidades morales aparecen también manifiestas. Pero lo que más sorprende es el abrupto cambio de persona («no olvides»; «dejáis») en versos sucesivos, con todo lo que conlleva de tierna familiaridad, de total abandono a la inspiración -el estro- del momento: nuestras hermanas ibarreñas seguramente no aman la academia.

Tampoco las vanguardias, por lo menos en este sector: digamos que una sensibilidad incipiente apunta al romanticismo sin pasar por el rococó. ¿Aguirre fecit? Esta hipótesis, históricamente descabellada, admite sin embargo una solución poligenética. El espíritu del siglo se manifiesta con abundancia en una sociedad tan heterogénea.

La conclusión de esta sección notable la confiaremos a un trozo sumamente interesante: abundantes preguntas retóricas, injertas en un contexto de religiosidad aspecífica (si no fuera por alusiones francamente «agitadas», como de Bastilla mística), podrían tender de nuevo a la oratoria de Granada. Mas un planteamiento demasiado problemático, con toda la serenidad del sobreentendido pacífico, nos hacen excluir la primera hipótesis.

17 Démosle sin más la palabra: 


\begin{abstract}
¿Qué cautiverios son éstos, intacta Virgen María?

¡La que siempre ha sido libre, en estos tiempos cautiva!

¿Presa en cárceles la reina? ¿Tu majestad oprimida ${ }^{16}$ ?

¡Presa tu misericordia de aquella injusta justicia! Tú, ¿sentenciada al suplicio como si fueras precita? ¿Condenada al fuego siendo de los cielos alegría? ¡Oh espejo claro de Dios y de sus ojos la niña! ¿Cómo mal mirado el hombre no mira a Dios que te mira? ${ }^{17}$
\end{abstract}

Como puede verse enseguida, aquí abundan las paradojas: evianas, por supuesto. Pero la alternancia de preguntas y exclamaciones enfáticas no es propia del barroco americano, y tampoco el esquema, demasiado límpido para intérpretes avezados a lo complejo. Pese a las figuras entonces («injusta justicia», derecha antítesis) y a una indignación que se remonta lejos, la nitidez esencial de palabras y conceptos consiente, con su finura armónica, la intersección con el siguiente sector. Antes de llegar al cual, será menester ocuparnos también del Romance a San Francisco Xavier, una linda y misteriosísima alegoría.

Sueño, imagen de la muerte,

ladrón de la vida humana,

que a la cansada fatiga

das treguas en que descansa,

¿por qué si a todos aquietas

y el más pobre al cielo igualas,

sólo a mí robarme quieres

el tesoro de mi casa?

¿Por qué llegas a mis muros

tus engañosas escalas

y al dormido pensamiento

con torpe cariño asaltas? ${ }^{18}$

¿Pero es Sancho Panza (un Panza religiosa y caballerescamente instruido) el que habla aquí con imágenes tópicas? ¿O es un Góngora abundantemente provisto de tropos, y decidido por una vez a soltarlos en orden, así comme il faut, con "lopiña" regularidad?

Lo que prima es en todo caso el aspecto canónico; y también cierta insinceridad de escuela, con inquietudes emuladoras de las glorias conceptistas. De acuerdo: pero al planteamiento convencional de problemas seguirá dentro de poco una búsqueda muy real; y la plástica sonora tendrá también una oportuna utilización, como lo muestra el siguiente apartado.

\title{
Beta/gamma: intersección decretada por la melodía
}

21 Hay que escuchar en silencio esta suerte de himno patriótico:

¡Ay que las hojas del campo

deshoja tirano furor!,

y al compás furioso 


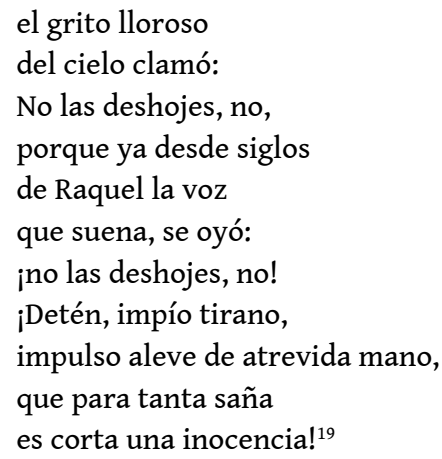

Los elementos naturalistas acompañan en robusta retórica una humanidad desolada, oprimida; y mientras un Dios bíblico «mira, desaprobando el holocausto» con la fuerza de una visión apocalíptica, los términos auditivos componen su línea de ininterrumpida coralidad, trazan la orquestación operística del Guaraní. Esto supera a Rousseau, a José Martí: es el grito de la "patria» moderna, preludia a la izquierda y la derecha, se oyen los acentos de Montalvo prestándole a Byron las arias de Verdi. Pero escuchemos más:
Llorar como Redentor
en la aurora de tal día,
será llorar de alegría
que también llora el amor;
llorad, mi Jesús, llorad,
que vuestras lágrimas son
la más sonora canción
que canta mi libertad.
Vuestro gusto es el dolor
y como de mí os doléis,
no me espanto que lloréis,
Niño, si tenéis amor ${ }^{20}$.

23 No está mal, un caudillo divino. Y ni hablar de «la más sonora canción, que canta mi libertad»: metáfora ardiente, acentos conmovidos e impensables un siglo -unas décadas- antes.

24 Ahora, en cuanto a términos alegóricos tenemos uno estupendo, que adscribiremos decididamente a esta línea todavía melódica, pero afectivamente desbordante. Helo aquí, estupendo como un fragmento sáfico:

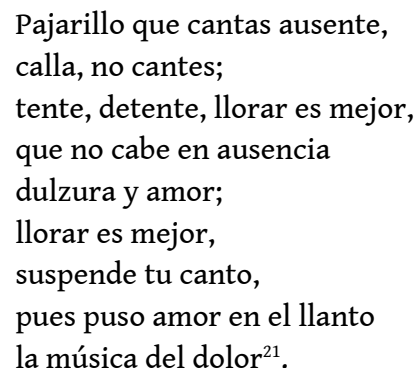

25 ¿También la anadiplosis? Nos encontramos al límite de la poesía anterior, en vísperas de acontecimientos internos decisivos ${ }^{22}$. El barroco americano, algo lento al principio, recupera posiciones anticipándose al romanticismo; engulle rápidamente el siglo de las luces con superficies diáfanas que ocultan, en profundidad, «la música del dolor». 


\section{Gamma: rogativas} espontánea llaneza, muy propia del género.

La causa de tanto enojo

los desmanes nuestros son, corrígelos blandamente por tu pura concepción. Llorando nuestros delitos con excesivo dolor, suplicamos nos perdones por tu pura concepción.

Tus hijas somos, al cabo, aunque indignas de tu amor, muestra, pues, ser nuestra madre, por tu pura concepción. A Vos, casta sunamita, claro sol y bella aurora, a voces pedimos todas misericordia, Señora. A Vos, espejo del alma, en quien la pureza mora, humildes hijas pedimos misericordia, Señora. Si es la miserable culpa destas fiebres causadora, arrepentidas clamamos misericordia, Señora ${ }^{24}$. «Si es amor, jay, Dios, qué dicha! Si son celos, jay de mí!». Nos preguntamos qué pasó con la certidumbre inicial. ¿Por qué debe replantearse la cuestión de la culpabilidad y la gracia, y cómo vuelve a aflorar Pascal luego del paréntesis tridentino? No esperábamos 
ahora las tormentas del agustinismo, especialmente en una materia tan llana y con reglas de pura ortodoxia. Mas todo se nos antoja difícil en estas postrimerías coloniales: complicado e imprevisto. La poesía tardobarroca empieza en América un metro quejumbroso, decide «arrojar la lira» ${ }^{25}$, colgándola significativamente de un ciprés. Levanta dudas, exclama enfática, mueve objeciones. Y termina empujando la barcarola de Hoffmann con un viento de marina inglesa, y la certeza de un adelanto histórico.

\section{BIBLIOGRAFÍA}

Barrera Isaac Jesús, Historia de la Literatura Ecuatoriana, Quito, Casa de la Cultura Ecuatoriana, 1954.

Carrión Alejandro, Antología general de la poesía ecuatoriana durante la colonia española, Quito, Grafiesa, 1992.

Castelo Rodríguez Hernán, Literatura en la Audiencia de Quito. Siglo XVIII, Ecuador, Casa de la Cultura Ecuatoriana, Núcleo de Tungurahua, 2002.

Di Patre Patrizia y Mafla Mercedes, «Disolución de patrones épico-amorosos en la literatura ecuatoriana tardobarroca (Aguirre, Velasco)», Espéculo. Revista de estudios literarios, n. 40, 2008.

Di Patre Patrizia, «Dante, Petrarca y Góngora en una despedida eviana», Dicenda, Cuadernos de filología hispánica, n. XXIX , 2001, p. 121-30.

Di Patre Patrizia, El lente deformador de la poesía barroca ecuatoriana. De próxima publicación en el volumen compilatorio del VII Congreso Internacional de Literatura, Memoria e Imaginación de Latinoamérica y el Caribe (Quito, 24-6 de agosto de 2011).

Evia Jacinto de, Ramillete de varias flores poéticas, México, Labrador-Di Franco eds., 2009.

López Alejandro, Datos sobre poesía religiosa e inédita del siglo XVIII, Ambato, Imprenta de Tungurahua, 1889.

Teresa de Jesús Santa, Libro de las fundaciones, I, Espasa-Calpe, Madrid, 1957.

\section{NOTAS}

1. Trabajo realizado con financiamiento de la Pontificia Universidad Católica del Ecuador.

2. En una colección que ocupaba dos voluminosos tomos, extractados por el canónigo en un breve folleto de 22 páginas (Alejandro López, Datos sobre poesía religiosa e inédita del siglo XVIII, Ambato, Imprenta de Tungurahua, 1889). Debido a la pérdida -quizá irreversible- de los originales, esta muestra fragmentaria adquiere un interés enorme. Para ulteriores datos remito a las obras siguientes: Isaac J. Barrera, Historia de la Literatura Ecuatoriana, Quito, Casa de la Cultura Ecuatoriana, 1954, II, pp. 97-103; Hernán Rodríguez Castelo, Literatura en la Audiencia de Quito. Siglo XVIII, Ecuador, Casa de la Cultura Ecuatoriana, Núcleo de Tungurahua, 2002, pp. 1498-1502. Los fragmentos reportados en este ensayo se citan de la asequible edición antológica compuesta por 
Alejandro Carrión: Antología general de la poesía ecuatoriana durante la colonia española, Quito, Grafiesa, 1992, pp. 312-323.

3. Para estas temáticas y autores sugiero la consulta de los siguientes artículos: Patrizia Di Patre y Mercedes Mafla, «Disolución de patrones épico-amorosos en la literatura ecuatoriana tardobarroca (Aguirre, Velasco)», Espéculo. Revista de estudios literarios, n. 40, 2008; Patrizia Di Patre, «Dante, Petrarca y Góngora en una despedida eviana», Dicenda, Cuadernos de filología hispánica, n. XXIX , 2001, pp.121-30; Patrizia Di Patre, El lente deformador de la poesía barroca ecuatoriana, conferencia magistral presentada en el VII Congreso Internacional de Literatura, Memoria e Imaginación de Latinoamérica y el Caribe, de próxima publicación en el respectivo volumen compilatorio.

4. Carrión, Antología, op. cit., p. 317.

5. Jacinto de Evia, Ramillete de varias flores poéticas, México, Labrador-Di Franco eds., 2009, pp. 133-134.

6. He dedicado a este tema especial consideración en el op. cit. El lente deformador.

7. Como se muestra en el trabajo citado supra, «A raíz del viaje ultramarino [...] el esfuerzo lingüístico de generar una continuidad analítica manifiesta el quebrantamiento semántico. Ya condicionado por un objeto desbordante, el registro no puede sino apuntar a los vacíos, con sugerencias reveladoras de fracturas». Es así como «la metapoesía de la reflexión metafórica induce, con la parodia, el abandono de la figura» (ibid.).

8. Carrión, Antología, op. cit., p. 316.

9. Ibid., p. 316.

10. Cf. Si tu mayor voluntad. Ibid., p. 319.

11. Ibid., p. 315.

12. Tendencia realmente emblemática, ampliamente documentada en el texto congresual El lente deformador, citado arriba.

13. Carrión, Antología, cit., p. 319.

14. Carrión, Antología, op. cit., p. 317.

15. Ibid., p. 319.

16. Cf. las Fundaciones de santa Teresa, I, III, 9 vo , 29-33: «¡Oh válgame Dios! Cuando yo vi a Su Majestad puesto en la calle, en tiempo tan peligroso como ahora estamos por estos luteranos, ¡qué fue la congoja que vino a mi corazón!». Santa Teresa de Jesús. Libro de las fundaciones, I, Espasa-Calpe, Madrid, 1957.

17. A una imagen de María condenada al fuego. Carrión, Antología, op. cit., pp. 320-321.

18. Romance a san Francisco Xavier. Ibid., p. 320.

19. A los santos inocentes. Ibid., p. 318.

20. Llanto de amor del niño Jesús. Ibid., p. 318.

21. Alegoría. Ibid., p. 323.

22. Aguirre es el punto culminante del proceso descrito. Su lenguaje «recompuesto», melódico -a raíz de las líneas quebradas, en tensión-, es señal de una incorporación ampliada, la adquisición científica de un mundo más vasto. Pero revela también la angustia de la conquista, más patente por el contraste. Tocará al ilustre desterrado recuperar la armonía del instrumento lingüístico, aunque con la conciencia de un vacío existencial.

23. Rogativa. Ibid., p. 320.

24. Ibid., pp. 321-322.

25. Cf. Juan de Velasco, A una musa que enfermó por no dormir. Ibid., 207-208. 


\section{AUTOR}

\section{PATRIZIA DI PATRE}

Pontificia Universidad Católica del Ecuador 